\section{(6) OPEN ACCESS}

REVIEW

\title{
Cerebrospinal fluid biomarkers in parkinsonian conditions: an update and future directions
}

\author{
Nadia Magdalinou, ${ }^{1}$ Andrew J Lees, ${ }^{1}$ Henrik Zetterberg ${ }^{1,2}$
}

${ }^{1}$ Department of Molecular Neuroscience, UCL Institute of Neurology, London, UK ${ }^{2}$ Clinical Neurochemistry Laboratory, Institute of Neuroscience and Physiology, The Sahlgrenska Academy at the University of Gothenburg, Mölndal, Sweden

Correspondence to Dr Nadia Magdalinou, Reta Lila Weston Institute, UCL Institute of Neurology, 1 Wakefiled Street, London WC1N 1PJ, UK n.magdalinou@ucl.ac.uk

Received 3 January 2014 Revised 17 February 2014 Accepted 24 February 2014 Published Online First 1 April 2014
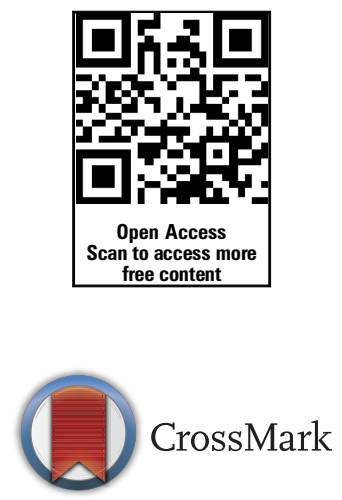

To cite: Magdalinou N, Lees AJ, Zetterberg $\mathrm{H}$. J Neurol Neurosurg Psychiatry 2014;85: 1065-1075.

\section{ABSTRACT}

Parkinsonian diseases comprise a heterogeneous group of neurodegenerative disorders, which show significant clinical and pathological overlap. Accurate diagnosis still largely relies on clinical acumen; pathological diagnosis remains the gold standard. There is an urgent need for biomarkers to diagnose parkinsonian disorders, particularly in the early stages when diagnosis is most difficult. In this review, several of the most promising cerebrospinal fluid candidate markers will be discussed. Their strengths and limitations will be considered together with future developments in the field.

\section{INTRODUCTION}

Idiopathic Parkinson's disease (iPD) is a progressive neurological disorder initially described as a clinical entity by James Parkinson and then embellished by Charcot and other nineteenth-century physicians, including Trousseau, Gowers and Erb. It is a clinical construct, based upon the presence of bradykinesia accompanied by at least one other characteristic feature, such as resting tremor, rigidity and impaired postural reflexes. ${ }^{1}$ The signs and symptoms are usually asymmetrical at onset and, typically, there is a good response to levodopa treatment.

'Parkinson-plus' or 'atypical parkinsonism' are terms that refer to a heterogeneous group of neurodegenerative disorders that may masquerade particularly in the early stages of the disease as Parkinson's disease (PD). ${ }^{2}$ The 'plus' or 'atypical' descriptor indicates the presence of additional characteristics not usual in patients with iPD, such as early autonomic disturbance and pyramidal signs exhibited by patients with multiple system atrophy (MSA), supranuclear gaze palsy and frontal/dysexecutive syndrome by those with progressive supranuclear palsy (PSP), dystonia and myoclonus in corticobasal degeneration (CBD) and early postural instability and falls by all of them. Another disease that could be classified as an atypical parkinsonian disorder is dementia with Lewy bodies (DLB), where dementia onset is before or within a year of onset of extrapyramidal features. The earlier onset of dementia differentiates DLB from Parkinson's disease dementia (PDD).

Atypical parkinsonian disorders account for less than $10 \%$ of all parkinsonism and rarely respond with sustained improvement to levodopa. They usually follow a much more aggressive disease course than $\mathrm{PDD}$ and are characterised by atrophy to several different cortical and subcortical networks. Furthermore, atypical parkinsonism has been described in other conditions, such as Alzheimer's disease (AD) and frontotemporal dementia (FTD).

\section{PATHOLOGY}

Protein misfolding and aggregation is seen with many neurodegenerative diseases. Based on pathological findings, parkinsonian syndromes are classified into $\alpha$-synucleinopathies (PD, DLB and MSA) and primary tauopathies (PSP and CBD). For pathological lesions used in postmortem diagnosis of parkinsonism, see figure 1 .

$\alpha$-Synuclein $(\alpha-$ Syn) has been found to be the major constituent of the intracellular aggregates in Lewy bodies and Lewy neurites (pathological hallmark of PD and DLB) and in the glial cytoplasmic inclusions in MSA. ${ }^{3}{ }^{4}$ The presence of abnormally aggregated tau proteins in the form of neurofibrillary tangles, for example, are diagnostic of PSP. ${ }^{5}$ Tau-positive intracellular inclusions are the neuropathological findings in CBD. ${ }^{6}$ Even though there are also neurofibrillary tangles in $\mathrm{AD}, \mathrm{A} \beta$ plaques are closely tied to the primary disease process and thus $\mathrm{AD}$ is considered to be a secondary tauopathy. FTD can also have underlying tau pathology.

There is often some overlap between syncleinopathies and tauopathies (for a review, see ref. 7). Co-occurrence of tau and $\alpha$-Syn pathology has been found in neurons and oligodendrocytes in $\mathrm{AD}, \mathrm{PD}$ and DLB. ${ }^{8} \alpha-$ Syn has complex and dynamic interactions with tau. Each of these two proteins has the tendency to seed the aggregation of the other. ${ }^{9} \alpha$-Syn induces aggregation and polymerisation of tau, which promotes formation of intracellular amyloid-tau inclusions. ${ }^{10}$ Similar interactions have been described between $\alpha$-Syn and A $\beta$ pathology. ${ }^{11}$

\section{GENETICS}

Recent advances in genetics have shed light on the underlying pathophysiology because mutations in the gene for each misfolded protein can give rise to an inherited form of a relevant neurodegenerative condition. For example, rare hereditary forms of PD can be caused by mutations affecting the gene coding for $\alpha$-Syn (SNCA); PARK1 (missense) and PARK4 (duplication, triplication). ${ }^{12}$ Furthermore, in both PD and to a lesser extent in MSA, population studies demonstrated an association between disease risk and distinct single-nucleotide polymorphisms in SNCA. DJ-1(PARK7) mutations can lead to rare forms of autosomal-recessive PD, pointing towards mitochondrial damage/oxidative stress pathways driven pathogenesis. ${ }^{13}$ Even though PD is not a 'tauopathy', population studies also showed variants in tau (MAPT) gene, particularly the $\mathrm{H} 1$ haplotype, as another risk factor for $\mathrm{PD}$ (for a review, see ref. 14). Several tauopathies are 


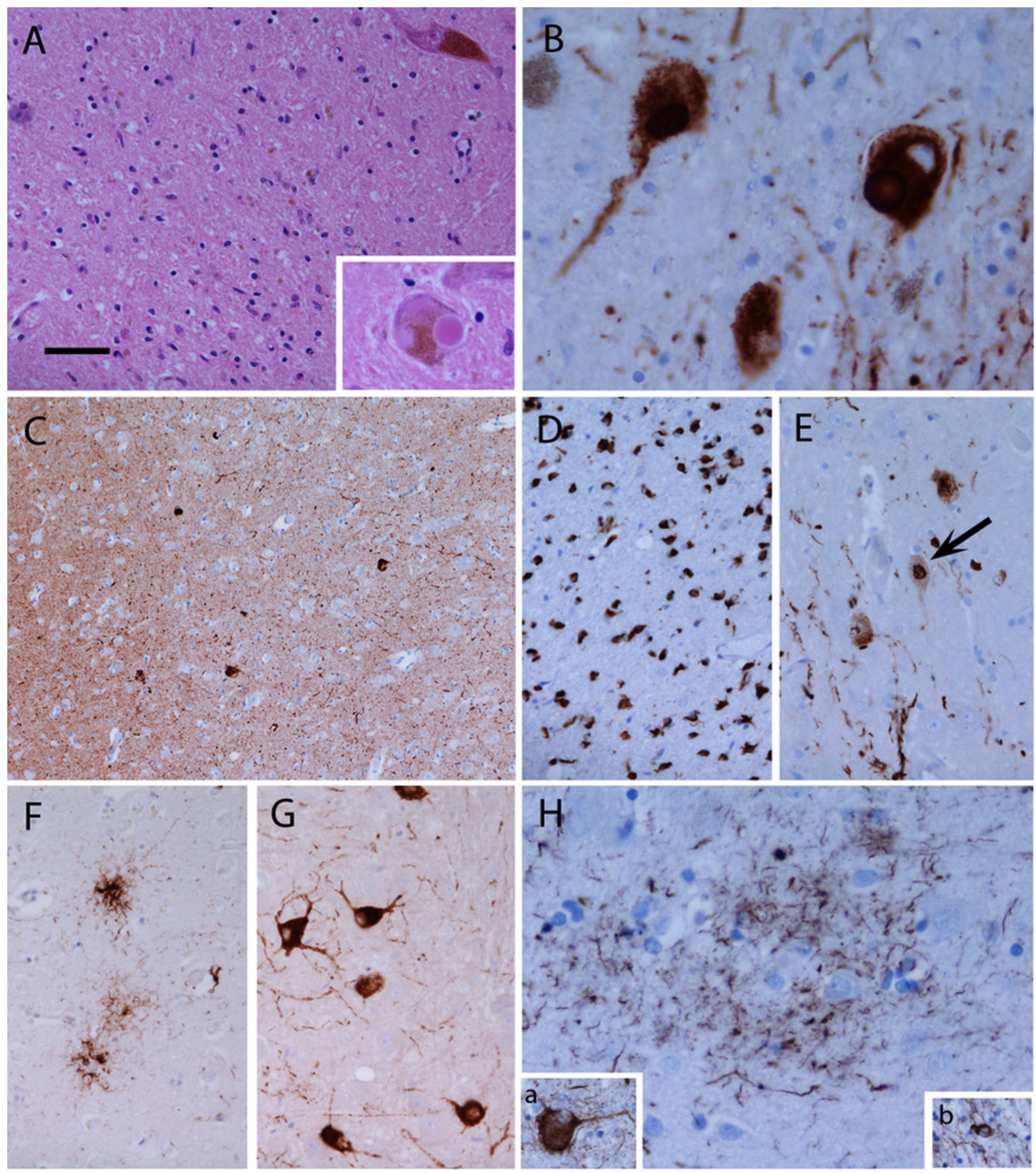

Figure 1 In Parkinson's disease (PD), there is loss of pigmented neurons from the substantia nigra and remaining neurons may be very sparse (A). Lewy bodies can be observed in residual neurons ( $A$, inset) and are highlighted, together with Lewy neuritis, using $\alpha$-synuclein immunohistochemistry (B). Lewy bodies and Lewy neurites may be present in significant numbers in the neocortex (C, frontal cortex). In multiple system atrophy (MSA), $\alpha$-synuclein is primarily deposited in the form of glial cytoplasmic inclusions in oligodendrocytes ( $D$, putamen) and may also form inclusions in neuronal cytoplasm and nuclei (arrow) ( $E$, pontine nuclei). In progressive supranuclear palsy tau forms, aggregates in neurons and glia, giving rise to tufted astrocytes ( $F$, caudate) and neurofibrillary tangles (G, pontine nuclei). A characteristic feature of corticobasal degeneration (CBD) is the astrocytic plaque, formed from aggregated tau in the distal processes of astrocytes ( $H$, parietal cortex). In CBD, tau also accumulates in neurons in the form of neurofibrillary tangles ( $H$, inset a) and in oligodendrocytes as coiled bodies $(H$, inset b). (A) Haematoxylin and eosin; (B-D) $\alpha$-synuclein immunohistochemistry; $(F-H)$ tau immunohistochemistry. Bar in $(A)$ represents $100 \mu m$ in $(C) ; 50 \mu m$ in $(A, D-G) ; 25 \mu \mathrm{m}$ in inset A, B and H. Pathological images kindly provided by Dr Janice Holton, Queen Square Brain Bank for Neurological Disorders, London.

associated with variants in MAPT, including CBD, FTD linked to chromosome 17 (FTDP-17T) and PSP. ${ }^{15}$ The fact that the $M A P T /$ tau haplotype also shows an association with PD strongly suggests that the pathogenic cascades in the tauopathies may be related to those in the synucleinopathies. ${ }^{16}$

\section{DIAGNOSTIC CHALLENGES}

Accurate diagnosis of parkinsonian disorders still relies heavily on clinical acumen, although imaging and ancillary investigations may be helpful in some situations. In one postmortem series, $24 \%$ of patients clinically diagnosed with idiopathic PD by a consultant neurologist during life were found to have an alternative diagnosis. ${ }^{1}$

\section{CEREBROSPINAL FLUID BIOMARKERS}

A biomarker is "a characteristic that is objectively measured and evaluated as an indicator of normal biological processes, pathogenic processes or pharmacologic response to a therapeutic intervention". ${ }^{17}$ An 'ideal' biomarker should be sensitive, reproducible, closely associated with the disease process, non-invasive and inexpensive.

Cerebrospinal fluid (CSF) has more physical contact with the brain than any other fluid and as such represents a potentially reliable biomarker source. Unlike plasma, CSF is not separated from the brain by the tightly regulated blood-brain barrier. Proteins/peptides that may be directly reflective of brain specific activities or disease pathology would most likely diffuse into the CSF. Furthermore, CSF can be tested serially, which makes possible the study of protein changes reflecting the evolving pathology throughout the clinical course of the disease. This is preferable to pathological studies, which only reveal the terminal changes of a disease process that has developed over decades.

\section{HISTORICAL BACKGROUND}

CSF has been widely investigated in parkinsonian disorders and is considered to offer the most promising insights into the 
disease process. Historically, because of dopaminergic abnormalities in parkinsonism, the first compounds to be tested as potential markers were dopamine and other monoamines and their metabolites. In the 1960s and 1970s, reduced CSF monoamine concentrations (homovanillic acid and 5-hydroxyindoleacetic acid) were found in patients with parkinsonism and dementia. ${ }^{18}$ A study conducted at the National Hospital, Queen Square, London, assessed the effect of levodopa treatment in CSF homovanillic acid concentration of PD patients. Before levodopa treatment, homovanillic acid concentration was low in all patients, while after treatment it rose to a level that correlated significantly with the levodopa dose. ${ }^{19}$

As these metabolic results were prone to be influenced by a multitude of other factors, ${ }^{7}$ the quest went further to investigate a priori defined compounds, such as $\alpha$-Syn and tau. These were tested in patients and in healthy controls, looking for differences, patterns and associations. Even though several promising candidates exist, there is still no reliable biomarker.

\section{METHODS}

We reviewed the potential use of CSF proteins as biomarkers in parkinsonism, focusing on $\alpha$-Syn, neuronal injury markers and A $\beta 42$. In addition, we briefly reviewed the latest novel markers and the 'omics' approach. We performed a PubMed/Medline search and limited searches to studies reported in English and published after 2006, including antemortem, human, lumbar CSF; all studies included at least one parkinsonian cohort compared with healthy or neurological controls. We combined searches with 'Parkinson's disease', 'progressive supranuclear palsy', 'multiple system atrophy', 'corticobasal syndrome' (CBS), 'corticobasal degeneration', 'Parkinson's disease dementia', 'dementia with Lewy bodies', 'Lewy body dementia', 'parkinsonism', 'synucleinopathies', 'tauopathies', 'neurodegenerative diseases' with 'CSF biomarkers' and specific biomarkers (' $\alpha$-Syn', 'tau', 'phosphorylated tau', 'A $\beta 42$ ', 'neurofilaments', 'neuronal injury markers', 'inflammatory', 'metabolic' and 'oxidative stress markers'). Further references were found manually from identified publications. For a review of the earlier literature, not captured using the time limit of our search criteria, see Eller and Williams. ${ }^{20}$

\section{CSF BIOMARKER CANDIDATES IN PARKINSONISM A $\beta 42$}

$\mathrm{A} \beta 42$ is a 42 amino-acid long, aggregation-prone protein, derived from the proteolytic processing of amyloid precursor protein and is a major component of neuritic plaques in $\mathrm{AD}$. Cognitive impairment and dementia are much more common in parkinsonism than in the general population and have a detrimental effect on quality of life and life expectancy. The link between $\mathrm{A} \beta 42$ and PD and dementia has been studied extensively (see table 1 ).

In most studies, $A \beta 42$ is significantly reduced in PD compared with controls and is associated with worse cognitive performance. $^{21-25}$ However, other investigations showed no difference between PD and controls. ${ }^{26-30}$

Compta et $a l^{31}$ collected CSF from 27 non-demented PD patients and followed them over time. Patients who converted to dementia within 18 months had a significantly lower baseline CSF A $\beta 42$ than the patients who remained non-demented.

DLB patients have the lowest CSF levels of A $\beta 42$ among the parkinsonian cohorts. ${ }^{25}$ 32-34 One study found that almost half of DLB patients had a CSF biomarker profile consistent with $\mathrm{AD},{ }^{33}$ which agrees with the knowledge of $\mathrm{A} \beta$ pathology in this disease. ${ }^{35-37}$

There is evidence that low $\mathrm{A} \beta 42$, a marker of $\mathrm{A} \beta$ plaque pathology, may predict cognitive decline in patients with $\mathrm{PD},{ }^{38}$ but other longitudinal studies with larger cohorts are necessary to clarify this further.

\section{$\alpha-S y n$}

$\alpha$-Syn is a 140 amino-acid long protein that localises to presynaptic terminals and is widespread in the brain, comprising $1 \%$ of cytosolic protein. In presynaptic terminals, $\alpha$-Syn is present in close proximity to the synaptic vesicles. The precise

Table 1 CSF A 342 in parkinsonian disorders

\begin{tabular}{|c|c|c|}
\hline Research groups & Participants & Main findings \\
\hline Kang et $a l^{21}$ & PD $n=39$ (drug-naïve patients), HC $n=63$ & Decrease in PD vs $\mathrm{HC}$ \\
\hline Compta et $a l^{31}$ & $\begin{array}{l}\text { Baseline: PD } n=27 \text { (non-demented) } \\
18 \text { month follow- } u p: P D n=16 \text { (non-demented), PD } n=11 \text { (dementia converters) }\end{array}$ & Decrease in dementia converters \\
\hline Bech et $a l^{32}$ & $P D n=22, P D D n=3, D L B n=11, M S A n=10, P S P n=20, C B D n=3$ & Decrease in DLB vs other disease groups \\
\hline Hall et $a l^{26}$ & PD $n=90, P D D n=33$, DLB $n=70, P S P n=45, C B D n=12, M S A n=48, A D n=48$, controls $n=107$ & Decrease in $A D>D L B+P D D$ \\
\hline Schoonenboom et $a l^{33}$ & DLB $n=52$, PSP $n=20, C B D n=16, A D n=512, F T D n=144$, VaD $n=34, C J D n=6$, controls $n=275$ & Decrease in $A D>V a D>D L B>C B D$ \\
\hline Parnetti et $a l^{27}$ & PD $n=38$, DLB $n=32, A D n=48$, FTD $n=31$, controls $n=32$ & $\begin{array}{l}\text { Decrease in AD, FTD+DLB vs PD and controls } \\
\text { No difference between PD and controls }\end{array}$ \\
\hline Andersson et $a \beta^{34}$ & DLB $n=47, P D D n=17, A D n=150$ & Decrease in DLB vs PDD \\
\hline Shi et $a l^{22}$ & $\begin{array}{l}\text { Discovery cohort: PD } n=126, \text { MSA } n=32, A D n=50 \text {, controls } n=137 \\
\text { Validation cohort: } P D n=83\end{array}$ & Slight decrease in PD and MSA vs controls \\
\hline Montine et $a l^{28}$ & $P D n=41, P D D n=11, A D n=49, H C n=150$ & Decrease in PDD vs $\mathrm{HC}$ \\
\hline Süssmuth et $a l^{29}$ & PSP-RS $n=20, P S P-P n=7, M S A-P n=11, M S A-C n=14, P D n=23$, controls $n=20$ & $\begin{array}{l}\text { No difference in parkinsonian syndromes } \\
\text { Lower in PSP-RS vs PSP-P }\end{array}$ \\
\hline Alves et $a l^{23}$ & $P D n=109, A D n=20, H C n=36$ & Decrease in $\mathrm{PD}$ vs $\mathrm{HC}$ \\
\hline Ohrfelt et $a l^{30}$ & PD $n=15, D L B n=15, A D n=66$, controls $n=55$ & Decrease in $A D+D L B$ vs controls and PD \\
\hline Compta et $a l^{24}$ & PD $n=20, P D D n=20, H C n=15$ & Decrease in PDD>PD vs $\mathrm{HC}$ \\
\hline Parnetti et $\left.a\right|^{25}$ & $P D n=20, P D D n=8, D L B n=19, A D n=23, H C n=20$ & Decrease in $\mathrm{DLB}>\mathrm{PDD}>\mathrm{PD}$ \\
\hline
\end{tabular}

$A D$, Alzheimer's disease; CBD, corticobasal degeneration; CJD, Creutzfeldt-Jakob disease; CSF, cerebrospinal fluid; DLB, dementia with Lewy bodies; FTD, frontotemporal dementia; HC, healthy controls; MSA, multiple system atrophy; MSA-C, multiple system atrophy cerebellar type; MSA-P, multiple system atrophy parkinsonian type; PD, Parkinson's disease; PDD, Parkinson's disease dementia; PSP, progressive supranuclear palsy; PSP-P, progressive supranuclear palsy-parkinsonism; PSP-RS, progressive supranuclear palsy-Richardson's syndrome; VaD, vascular dementia. 
function of $\alpha$-Syn is obscure, but it is speculated that its main role is in the control of neurotransmitter release. ${ }^{39}$ Although mostly considered an intracellular protein, $\alpha$-Syn is capable of transfer between cells leading to a speculation of a prion-like mechanism operating in PD pathology spread. ${ }^{40}$

$\alpha$-Syn can be modified by truncation, acetylation, phosphorylation, oxidation, nitrosylation, glycation or glycosylation. ${ }^{41}$ Lewy bodies are formed mostly of post-translationally modified $\alpha$-Syn. $\alpha$-Syn deposition is key in the pathogenesis of synucleinopathies. In vitro, similar to $\mathrm{AD}, \alpha$-Syn fibrillation involves $\alpha$-Syn oligomerisation followed by oligomer conversion into mature amyloid cultures, which are toxic to cultured neuronal cells. ${ }^{42}$

\section{Total $\alpha$-Syn (t- $\alpha$-Syn)}

Inconsistent results were initially reported in parkinsonian conditions with studies demonstrating considerable overlap of $\mathrm{t}-\alpha-\mathrm{Syn}$ in several neurodegenerative conditions. ${ }^{30} 43-45$ A consensus is now emerging, and the vast majority of recent studies (predominantly using ELISA techniques) have shown a reduction of $\mathrm{t}-\alpha-\mathrm{Syn}$ levels in PD compared with controls. ${ }^{21} 22264^{4-55}$ In addition, there is decreased $t-\alpha-S y n$ in other synucleinopathies, such as MSA and DLB, ${ }^{26} 4749505154$ without good discriminatory value between the groups (see table 2).

Mollenhauer et al assessed levels of $\mathrm{t}-\alpha-S y n$ in patients with synucleinopathies, patients with tauopathies and in neurological controls without neurodegenerative disease, first in a training set and then in a validation set. In the training set, a combination of $\mathrm{t}-\alpha-S y n, t-t a u$ and age differentiated synucleinopathies from neurological controls and $\mathrm{AD}$ with an area under the curve (AUC) of 0.908 . Only $\mathrm{t}-\alpha-S y n$ levels and not $\mathrm{t}$-tau or A $\beta 42$ discriminated PD and MSA from controls with a positive predictive value of $91 \% .^{54}$

Parnetti et al investigated whether the combination of t-tau, $\mathrm{p}$-tau and $\mathrm{t}-\alpha$-Syn can improve differentiation of PD from DLB, $\mathrm{AD}, \mathrm{FTD}$ and controls. They found an inverse correlation between $\mathrm{t}-\alpha-$ Syn and total tau in all subjects and a lack of specificity of CSF $\mathrm{t}-\alpha-$-Syn determination alone as a marker of synucleinopathy (sensitivity 94\%, specificity 25\%). However, t-tau/ $\mathrm{t}-\alpha-\operatorname{Syn}$ and $\mathrm{p}$-tau/t- $\alpha-S y n$ ratios were identified as possible biomarkers for PD (sensitivity $89 \%$, specificity $61 \%$ ). ${ }^{27}$

Shi et $a l^{22}$ also showed that a combination of $t-\alpha-S y n$ and $\mathrm{p}$-tau/t-tau could discriminate PD from MSA with a sensitivity of $90 \%$ and a specificity of $71 \%$, when blood contaminated samples were excluded. $\mathrm{t}-\alpha-$ Syn was decreased in PD and especially in MSA compared with controls.

In most studies, there was no correlation of $t-\alpha-S y n$ with disease duration or disease severity. Interestingly, gender-specific variations were reported in levels of $\mathrm{t}-\alpha-S y n .{ }^{47}$ Both Mollenhauer et $a l^{48}$ and Kang et $a l^{21}$ studied drug-naïve PD patients and still found reduction in $\mathrm{t}-\alpha-S y n$, so it was proven that this finding was not related to a dopaminergic medication effect. There are several theories why there is reduced $t-\alpha-S y n$ in PD, MSA and DLB. High brain levels of pathological $t-\alpha-S y n$ and low CSF levels may reflect a reduction of 'free' $t-\alpha-S y n$ circulating in the CSF. This could be similar to 'pathological protein trapping' reported for brain $\mathrm{A} \beta 42$ in $\mathrm{AD} \mathrm{CSF}^{56}$

\section{Oligomeric and phosphorylated $\boldsymbol{\alpha}$-Syn}

Tokuda et al evaluated soluble $\alpha$-Syn oligomers as potential early markers of PD and found that both the level of oligomeric $\alpha$-Syn and the oligomer/t- $\alpha$-Syn ratio were substantially higher in patients with PD (including those with mild and early-stage disease) compared with healthy controls and patients with nonneurodegenerative neurological conditions. CSF oligomer/ t- $\alpha$-Syn ratio had a sensitivity of $89.3 \%$ and a specificity of $90.6 \%$ for PD. ${ }^{57}$ These findings were replicated in two further, independent studies. ${ }^{58} 59$ Both oligomeric and phosphorylated oligomeric forms of $\alpha$-Syn were detected in postmortem ventricular CSF, which may be useful in distinguishing between PD, DLB and MSA. ${ }^{60}$ The results need to be replicated in larger groups of living patients.

\section{NEURONAL INJURY MARKERS}

Tau

Tau is important for the function of axonal microtubules and, as a result, plays an important role in the structural integrity of the neuron and axonal support. When hyperphosphorylated, it has reduced binding affinity for microtubules, causing their malfunction. At the same time, it adopts an abnormal conformation leading to aggregation and inclusion formation. ${ }^{61}$

\section{Total and phosphorylated tau (t-tau and p-tau)}

In the past, there were inconclusive results when assessing tau levels in CSF of parkinsonian patients (see table 3). In PD, most studies found normal values, ${ }^{23} 242526272930$ but lower levels were also reported. ${ }^{21} 2228$ In atypical parkinsonism, high t-tau levels were found in $\mathrm{DLB}^{25} 2734$ and low p-tau/t-tau ratio in MSA and PSP compared with PD. ${ }^{29}$ However, other investigations found no difference between parkinsonian syndromes. $^{22} 2630$ In particular, no significant change has been seen in PSP. ${ }^{26}$ Age, not diagnosis, is thought to be the strongest factor affecting t-tau protein levels. ${ }^{54}$

$\mathrm{t}$-tau and $\mathrm{p}$-tau may prove useful in differentiating $\mathrm{AD}$ from PD and can perhaps improve diagnostic accuracy when used in combination with other markers rather than on their own.

\section{Tau isoforms}

Imbalances in the homeostasis of tau isoforms with three(3R-tau) and four- (4R-tau) microtubule-binding repeat domains are important in neurodegenerative disease pathogenesis. In a normal adult brain, there are comparable levels of 3R- and $4 \mathrm{R}^{-62}$ but in PSP, CBD and FTDP-17 cases, the neurofibrillary tangles and glial inclusions are predominantly 4R, whereas Pick bodies in FTD are predominantly $3 \mathrm{R}-\operatorname{tau}^{63}$ and neurofibrillary tangles in $\mathrm{AD}$ contain both $3 \mathrm{R}$ - and 4R-tau isoforms.

Luk and colleagues had previously developed antibodies selective for the two isoforms and adapted an immuno-PCR procedure in order to detect the isoforms' miniscule amounts in the CSF. Decrease in 4R-tau isoform was found in PSP and AD compared with CBS, PDD and controls. There was no difference in 3R-tau. ${ }^{64}$

We think that $4 \mathrm{R}$-tau could be used as a marker of disease progression in PSP, but further large samples and longitudinal series are needed.

\section{Truncated tau forms}

Borroni and colleagues looked at full-length $(55 \mathrm{kDa})$ and truncated $(33 \mathrm{kDa})$ tau forms in several neurodegenerative diseases. In ratio with the full-length tau forms, the truncated tau forms (33 kDa/55 kDa forms) were substantially reduced in PSP compared with healthy controls (sensitivity $96 \%$ and specificity $85 \%$ PSP compared with PD/DLB; sensitivity $90 \%$ and specificity 76.2\% PSP compared with CBD). ${ }^{65}$ These fragments are proteolytic products of tau that were detected by immunoprecipitation techniques, which are more time consuming, less quantitative and more operator-dependent than ELISA techniques.

Findings were reproduced by the same group in another cohort of patients. ${ }^{66}$ However, these results were 
Table 2 CSF $\alpha$-synuclein in parkinsonian disorders

\begin{tabular}{|c|c|c|c|c|}
\hline Research groups & Participants & Analyte & Method & Main findings \\
\hline Van Dijk et $a l^{46}$ & $P D n=53, H C n=50$ & $\begin{array}{l}\text { t- } \alpha \text {-Syn } \\
\text { t- } \alpha \text {-Syn/ } \\
\text { t-protein ratio }\end{array}$ & TR-FRET & $\begin{array}{l}\text { Decrease in both } \mathrm{t}-\alpha-\text { Syn }+\mathrm{t}-\alpha-\text {-Syn/t-protein } \\
\text { ratio levels in PD vs HC }\end{array}$ \\
\hline Kang et al $2013^{21}$ & PD $n=39$ (drug-naïve patients), $\mathrm{HC} n=63$ & t- $\alpha-$ Syn & ELISA & Decrease in PD vs $\mathrm{HC}$ \\
\hline Wennström et al ${ }^{47}$ & $\begin{array}{l}P D n=38, P D D n=22, \text { DLB } n=33, A D n=46 \\
H C n=52\end{array}$ & t- $\alpha-$ Syn & ELISA & Decrease in $\mathrm{PDD}>\mathrm{PD}>\mathrm{DLB}$ vs $\mathrm{AD}+\mathrm{HC}$ \\
\hline Mollenhauer et al ${ }^{48}$ & $\begin{array}{l}\text { PD } n=78 \text { (de novo, drug-naïve patients), HC } \\
n=48\end{array}$ & t- $\alpha-S y n$ & ELISA (3rd generation) & Decrease in de novo PD patients vs $\mathrm{HC}$ \\
\hline Hall et $a l^{26}$ & $\begin{array}{l}\text { PD } n=90, P D D n=33, \text { DLB } n=70 \text {, PSP } n=45 \text {, } \\
\text { CBD } n=12, M S A n=48, A D n=48 \text {, controls } \\
n=107\end{array}$ & $\mathrm{t}-\alpha-\operatorname{Syn}$ & $\begin{array}{l}\text { Bead-based multi-analyte assay } \\
\text { (Luminex) }\end{array}$ & $\begin{array}{l}\text { Modest decrease in } A D>D L B+P D D>P D \\
+ \text { MSA vs controls, } A D \text { and PSP }\end{array}$ \\
\hline Aerts et $a l^{43}$ & $\begin{array}{l}\text { PD } n=58, M S A n=47, \text { DLB } n=3, \operatorname{VaD} n=22 \\
\text { PSP } n=10, C B D n=2\end{array}$ & t- $\alpha-\operatorname{Syn}$ & ELISA & No difference between groups \\
\hline Tateno et $a l^{49}$ & $\begin{array}{l}\text { PD } n=11, \text { DLB } n=6, M S A n=11, A D n=9 \text {, } \\
\text { controls } n=11\end{array}$ & t- $\alpha-$ Syn & ELISA & $\begin{array}{l}\text { Decrease in PD, DLB, MSA vs AD+ } \\
\text { controls } \\
\text { No difference among PD, DLB, MSA }\end{array}$ \\
\hline Wang et $a l^{50}$ & $\begin{array}{l}\text { Discovery cohort: } \\
\text { PD } n=83, M S A n=14, P S D n=30, A D n=25 \text {, } \\
\text { HC } n=51 \\
\text { Validation cohort: } \\
\text { PD } n=109, \text { MSA } n=20, \text { PSP } n=22, A D \\
n=50, H C n=71\end{array}$ & $\begin{array}{l}\text { t- } \alpha-S y n \\
p-\alpha-S y n \\
p-\alpha-S y n: \\
\text { t- } \alpha-S y n \text { ratio }\end{array}$ & $\begin{array}{l}\text { Bead-based multi-analyte assay } \\
\text { (Luminex) }\end{array}$ & $\begin{array}{l}\text { t- } \alpha \text {-Syn decrease in PD+MSA vs controls } \\
\text { Increase } \alpha \text {-Syn ratio in MSA vs PSP } \\
\text { Increase } \alpha \text {-Syn ratio in PD vs controls and } \\
\text { PSP }\end{array}$ \\
\hline Park et $a P^{58}$ & PD (drug-naïve) $n=23$, controls $n=18$ & $\begin{array}{l}\text { t- } \alpha-S y n \\
0-\alpha-S y n\end{array}$ & $\begin{array}{l}\text { Dual ELISA method for } \\
\text { simultaneous measurement of } \\
\text { t-and } 0-\alpha-\text { Syn }\end{array}$ & $\begin{array}{l}\text { t- } \alpha \text {-Syn: no difference } \\
\text { o- } \alpha \text {-Syn: increase in PD }\end{array}$ \\
\hline Mollenhauer et $a l^{54}$ & $\begin{array}{l}\text { Training cohort: PD } n=51, \text { DLB } n=55, \text { MSA } \\
n=29, \text { AD } n=62 \text {, controls } n=76 \\
\text { Validation cohort: PD } n=273, \text { DLB } n=66 \text {, } \\
\text { PSP } n=8, \text { MSA } n=15, N P H n=22 \text {, controls } \\
n=23\end{array}$ & t- $\alpha-S y n$ & ELISA (1st and 2nd generation) & $\begin{array}{l}\text { Decrease in PD, DLB, MSA vs AD, NPH, } \\
\text { PSP and controls } \\
\text { High degree of concordance in t- } \alpha \text {-Syn } \\
\text { levels between PD+MSA }\end{array}$ \\
\hline Parnetti et $a l^{27}$ & $\begin{array}{l}\text { PD } n=38, D L B n=32, A D n=48, F T D n=31 \text {, } \\
\text { controls } n=32\end{array}$ & $\begin{array}{l}\text { t- } \alpha-\text { Syn } \\
\text { t- } \alpha-\text { Syn/t-tau } \\
\text { ratio }\end{array}$ & ELISA & $\begin{array}{l}\text { t- } \alpha \text {-Syn decrease in all diseased groups } \\
\text { (especially DLB/FTD) } \\
\text { Ratio: decrease in PD vs all other diseased } \\
\text { groups }\end{array}$ \\
\hline Shi et $a l^{22}$ & $\begin{array}{l}\text { Discovery cohort: } P D n=126, \text { MSA } n=32 \\
\text { AD } n=50 \text {, controls } n=137 \\
\text { Validation cohort }: P D n=83\end{array}$ & t- $\alpha-$ Syn & $\begin{array}{l}\text { Bead-based multi-analyte assay } \\
\text { (Luminex) }\end{array}$ & Decrease in PD vs controls and AD \\
\hline Tokuda et $a l^{57}$ & $\begin{array}{l}\text { First cohort (all analytes): } \\
\text { PD } n=32 \text {, controls } n=28 \\
\text { Second cohort (o-asyn): } \\
P D n=25, A D n=35, P S P n=18 \text {, controls } \\
n=43\end{array}$ & $\begin{array}{l}\text { t- } \alpha-\text { Syn } \\
0-\alpha-S y n \\
0-\alpha-S y n: \\
\text { t- } \alpha-S y n \text { ratio }\end{array}$ & ELISA & $\begin{array}{l}\text { t- } \alpha \text {-Syn: trend towards decrease in PD } \\
0-\alpha-\text { Syn+ratio increase in PD }\end{array}$ \\
\hline Hong et $a l^{52}$ & $P D n=117, A D n=50, H C n=132$ & t- $\alpha-S y n$ & $\begin{array}{l}\text { Bead-based multi-analyte assay } \\
\text { (Luminex) }\end{array}$ & $\begin{array}{l}\text { Decrease in PD vs } A D \text { and controls (after } \\
\text { omitting samples with high haemoglobin } \\
\text { concentration) }\end{array}$ \\
\hline Noguchi- Shinohara et al ${ }^{44}$ & DLB $n=16, A D n=21$ & t- $\alpha-S y n$ & ELISA & No difference \\
\hline Spies et $a l^{45}$ & $\begin{array}{l}\text { DLB } n=40, A D n=131, \text { VaD } n=28, F T D \\
n=39\end{array}$ & t- $\alpha-S y n$ & ELISA & No difference \\
\hline Ohrfelt et $a l^{30}$ & $\begin{array}{l}P D n=15, D L B n=15, A D n=66 \text {, controls } \\
n=55\end{array}$ & t- $\alpha-$ Syn & ELISA & $\begin{array}{l}\text { Decrease in } A D \text {, no difference in parkinsonian } \\
\text { groups }\end{array}$ \\
\hline Mollenhauer et $a l^{53}$ & $\begin{array}{l}\text { PD } n=8, D L B n=38, A D n=13, C J D n=8 \text {, } \\
\text { controls } n=13\end{array}$ & t- $\alpha-S y n$ & ELISA (1st and 2nd generation) & $\begin{array}{l}\text { Marginal decrease in LBD and PD vs all other } \\
\text { groups }\end{array}$ \\
\hline Tokuda et $a l^{55}$ & PD $n=38$, controls $n=38$ & $t-\alpha-S y n$ & ELISA & Decrease in PD vs controls \\
\hline
\end{tabular}

AD, Alzheimer's disease; CBD, corticobasal degeneration; CJD, Creutzfeldt-Jakob disease; CSF, cerebrospinal fluid; DLB, dementia with Lewy bodies; FTD, frontotemporal dementia; HC, healthy controls; MSA, multiple system atrophy; NPH, normal pressure hydrocephalus; PD, Parkinson's disease; PDD, Parkinson's disease dementia; PSP, progressive supranuclear palsy; TR-FRET, time-resolved Förster's resonance energy transfer; VaD, vascular dementia.

not reproduced by another group, which did not find a reduced tau ratio in an independent cohort of PSP patients, ${ }^{67}$ speculating that the $33 / 55 \mathrm{kDa}$ bands seen are heavy and light IgG chains. Recent findings of other endogenous tau fragments in CSF suggest that specific assays for these fragments should be developed and evaluated in relation to different tauopathies. ${ }^{68}$

\section{Neurofilament light chain protein (NF-L)}

Neurofilaments are major structural elements, whose main role is to maintain the axonal calibre and neuronal shape and size. ${ }^{69}$ They are, thus, critical for the morphological integrity of neurons and for the conduction of nerve impulses along axons. They are composed of three subunits of different molecular weights: light, medium and heavy chain. 
Table 3 CSF neuronal injury markers: tau, neurofilament light chain (NF-L) and glial fibrillary acidic protein (GFAP) in parkinsonian disorders

\begin{tabular}{|c|c|c|c|c|}
\hline Research groups & Participants & Analyte & Method & Main findings \\
\hline Kang et $a l^{21}$ & PD n=39 (drug-naïve patients), HC $n=63$ & $\begin{array}{l}\mathrm{t} \text {-tau, } \\
\mathrm{p} \text {-tau }\end{array}$ & $\begin{array}{l}\text { Bead-based multi-analyte assay } \\
\text { (Luminex) }\end{array}$ & Decrease in t-tau+p-tau in PD vs controls \\
\hline Luk et $a l^{64}$ & $\begin{array}{l}\text { PDD } n=11, \text { PSP } n=44, C B S n=22, A D n=11 \text {, } \\
\text { controls } n=34\end{array}$ & $\begin{array}{l}3 R / 4 R \\
\text { isoforms }\end{array}$ & $\begin{array}{l}\text { Immuno-PCR (adapted from sandwich } \\
\text { ELISAs) }\end{array}$ & $\begin{array}{l}\text { Decrease in } 4 R \text {-tau in PSP and AD vs controls } \\
\text { Lower } 4 R \text {-tau in AD vs PDD } \\
\text {-No difference in } 3 \text {-tau }\end{array}$ \\
\hline Hall et al $2012^{26}$ & $\begin{array}{l}\text { PD } n=90, \text { PDD } n=33, \text { DLB } n=70, \text { PSP } n=45 \text {, } \\
\text { CBD } n=12, M S A=48, A D n=48 \text {, controls } \\
n=107\end{array}$ & $\begin{array}{l}\text { t-tau, } \\
\text { p-tau } \\
\text { NF-L }\end{array}$ & $\begin{array}{l}\text { Bead-based multi-analyte assay } \\
\text { (Luminex) }\end{array}$ & $\begin{array}{l}\text { Increased t-and } p \text {-tau in AD vs DLB+PDD } \\
\text { NF-L differentiates PD from atypical } \\
\text { parkinsonism }\end{array}$ \\
\hline Bech et $\left.a\right|^{32}$ & $\begin{array}{l}P D n=22, P D D n=3, D L B n=11, M S A n=10, P S P \\
n=20, C B D n=3\end{array}$ & NF-L & ELISA & $\begin{array}{l}\text { Higher NF-L levels in atypical parkinsonian } \\
\text { disorders vs PD } \\
\text { - No difference between parkinsonian groups }\end{array}$ \\
\hline Andersson et $a^{34}$ & DLB $n=47, P D D n=17, A D n=150$ & $\begin{array}{l}\mathrm{t} \text {-tau, } \\
\mathrm{p} \text {-tau }\end{array}$ & ELISA & Increased t-tau in DLB vs PDD \\
\hline Shi et $a l^{22}$ & $\begin{array}{l}\text { Discovery cohort: } P D n=126, \text { MSA } n=32, A D \\
n=50 \text {, controls } n=137 \\
\text { Validation cohort: } P D n=83\end{array}$ & $\begin{array}{l}\mathrm{t} \text {-tau, } \\
\mathrm{p} \text {-tau }\end{array}$ & $\begin{array}{l}\text { Bead-based multi-analyte assay } \\
\text { (Luminex) }\end{array}$ & $\begin{array}{l}\text {-Decrease in PD vs to controls } \\
\text {-Decrease in PD+MSA vs AD }\end{array}$ \\
\hline $\begin{array}{l}\text { Parnetti et al } \\
2011^{27}\end{array}$ & $\begin{array}{l}\text { PD } n=38, D L B \quad n=32, A D n=48, F T D n=31 \text { ， } \\
\text { controls } n=32\end{array}$ & $\begin{array}{l}\text { t-tau, } \\
\mathrm{p} \text {-tau }\end{array}$ & ELISA & $\begin{array}{l}\text { Increase in AD>FTD>DLB vs PD and controls } \\
\text { No difference between PD and controls }\end{array}$ \\
\hline Kuiperij et al ${ }^{102}$ & NA & $\begin{array}{l}33 / 55 \\
\mathrm{kDa} \text { tau } \\
\text { forms }\end{array}$ & $\begin{array}{l}\text { Immunoprecipitation assay and } \\
\text { western blotting }\end{array}$ & $\begin{array}{l}\text { Not able to detect tau form ratio } \\
\text { Suggested that } 33 / 55 \mathrm{kDa} \text { bands seen are } \\
\text { heavy and light IgG chains }\end{array}$ \\
\hline Borroni et al $\left.\right|^{103}$ & PSP $n=18, C B S n=16$, FTD $n=28$, controls $n=25$ & $\begin{array}{l}33 / 55 \\
\mathrm{kDa} \text { tau } \\
\text { forms }\end{array}$ & $\begin{array}{l}\text { Immunoprecipitation assay and } \\
\text { western blotting }\end{array}$ & $\begin{array}{l}\text { tau form ratio significantly reduced in PSP vs } \\
\text { other groups }\end{array}$ \\
\hline $\begin{array}{l}\text { Constantinescu } \\
\text { et } a l^{71}\end{array}$ & $\begin{array}{l}P D n=10, M S A n=21, P S P n=14, C B D n=11, H C \\
n=59 \\
(\times 2 \text { consecutive samples })\end{array}$ & $\begin{array}{l}\text { NF-L } \\
\text { GFAP }\end{array}$ & ELISA & $\begin{array}{l}\text { NF-L: normal levels in PD, elevated in MSA, } \\
\text { PSP+CBD } \\
\text { No statistical significance overtime } \\
\text { GFAP: no difference }\end{array}$ \\
\hline Montine et $a l^{28}$ & $P D n=41, P D D n=11, A D n=49, H C n=150$ & $\begin{array}{l}\text { t-tau, } \\
\mathrm{p} \text {-tau }\end{array}$ & $\begin{array}{l}\text { Bead-based multi-analyte assay } \\
\text { (Luminex) }\end{array}$ & $\begin{array}{l}\text { t-tau: no difference between parkinsonian } \\
\text { groups } \\
\text { - p-tau: reduced in PD vs HC }\end{array}$ \\
\hline Süssmuth et $a l^{29}$ & $\begin{array}{l}\text { PSP-RS } n=20 \text {, PSP-P } n=7 \text {, MSA-P } n=11 \text {, MSA-C } \\
n=14, P D n=23 \text {, controls } n=20\end{array}$ & $\begin{array}{l}\text { t-tau, } \\
\text { p-tau } \\
\text { GFAP }\end{array}$ & ELISA & $\begin{array}{l}\text { p-tau/t-tau ratio lower in PSP and MSA vs PD } \\
\text { GFAP: increase in parkinsonian syndromes } \\
\text { (no difference between disease groups) }\end{array}$ \\
\hline Alves et $a l^{23}$ & $P D n=109, A D n=20, H C n=36$ & $\begin{array}{l}\text { t-tau, } \\
\text { p-tau }\end{array}$ & ELISA & No difference between PD and controls \\
\hline Ohrfelt et $a \beta^{30}$ & PD $n=15$, DLB $n=15, A D n=66$, controls $n=55$ & $\begin{array}{l}\text { t-tau, } \\
\text { p-tau }\end{array}$ & ELISA & No difference between parkinsonian groups \\
\hline Compta et $a l^{24}$ & $P D n=20, P D D n=20, H C n=15$ & $\begin{array}{l}\text { t-tau, } \\
\text { p-tau }\end{array}$ & ELISA & $\begin{array}{l}\mathrm{t} \text { - and } \mathrm{p} \text { - tau: increase in PDD vs PD and } \\
\text { controls }\end{array}$ \\
\hline Parnetti et al ${ }^{25}$ & $\begin{array}{l}\text { PD } n=20, P D D n=8, D L B n=19, A D n=23, H C \\
n=20\end{array}$ & $\begin{array}{l}\text { t-tau, } \\
\mathrm{p} \text {-tau }\end{array}$ & ELISA & $\begin{array}{l}\text { t-tau: DLB }>\text { PDD }>\text { controls } \\
\text { p-tau: no difference between parkinsonian } \\
\text { groups }\end{array}$ \\
\hline Borroni et $a^{65}$ & $\begin{array}{l}\text { PSP } n=21, C B S n=20, \text { FTD } n=44, A D n=15, P D \\
n=10, D L B n=15, \text { controls } n=27\end{array}$ & $\begin{array}{l}33 / 55 \\
\mathrm{kDa} \text { tau } \\
\text { forms }\end{array}$ & $\begin{array}{l}\text { Semiquantitative immunoprecipitation } \\
\text { and western blotting }\end{array}$ & $\begin{array}{l}\text { tau forms significantly reduced in PSP vs controls } \\
\text { and other neurodegenerative diseases }\end{array}$ \\
\hline $\begin{array}{l}\text { Brettschneider } \\
\text { et } a l^{70}\end{array}$ & $\begin{array}{l}\text { PD } n=22 \text {, MSA } n=21, \text { PSP } n=21, C B D n=6 \text {, } \\
\text { controls } n=45\end{array}$ & $\mathrm{NF}-\mathrm{H}$ & ELISA & $\begin{array}{l}\text { Increased in MSA and PSP vs PD, CBD and } \\
\text { controls }\end{array}$ \\
\hline
\end{tabular}

Neurofilament heavy chain (NF-H) forms an important component of the cytoskeleton. Higher CSF levels of NF-H were found in PSP and MSA compared with PD, CBD and neurological controls. ${ }^{70}$

Neurofilament light chain forms the backbone of neurofilaments and can self-assemble. Increased levels in CSF reflect axonal degeneration of large myelinated axons. Recent studies showed consistent results in differentiating PD from atypical parkinsonian conditions ${ }^{26} 3271$ but not in discriminating between atypical parkinsonian syndromes. Consecutive analyses of CSF showed no increase in NF-L levels with disease progression. $^{71}$
NF-L can be useful in the differential diagnosis of PD versus other neurodegenerative conditions as it is very sensitive in detecting more aggressive neuronal death than occurs in PD.

\section{Glial fibrillary acidic protein}

Glial fibrillary acidic protein (GFAP) is a protein predominantly expressed in fibrillary astrocytes. Disintegration of astroglial cells postacute brain injury can lead to high CSF GFAP levels. Süssmuth et $a l^{29}$ showed that there are increased levels in parkinsonian syndromes compared with controls (patients with other neurological disorders), but there was no difference between diseased groups. However, another group found 
similar GFAP levels in parkinsonian syndromes and healthy controls without significant change over time. ${ }^{71}$

\section{OTHER CANDIDATE MARKERS}

\section{Oxidative stress markers}

DJ-1

DJ-1 is a multifunctional protein involved in many processes. It is thought to have a protective role in oxidative stress during neurodegeneration (table 4). As we have already discussed, it has been linked to autosomal-recessive PD. Results on DJ-1 as a CSF biomarker have been inconsistent so far. One study showed decreased levels in PD compared with controls with a sensitivity of $90 \%$ and a specificity of $70 \%,{ }^{52}$ whereas another showed no difference among parkinsonian syndromes ${ }^{72}$ and the most recent one demonstrated significant increase in MSA compared with PD and controls. ${ }^{73}$ The diagnostic accuracy for discriminating MSA from PD was improved by combining DJ-1 levels with $\mathrm{t}$-tau and p-tau levels.

\section{8-Hydroxydeoxyguanosine (8-OHdG)}

8 -OHdG is a marker of oxidation and mitochondrial dysfunction in neurodegeneration and malignancy. CSF 8-OHdG levels were increased in non-demented PD patients compared with controls and there was a negative correlation with MMSE levels in PDD. ${ }^{74}$

\section{Urate}

Urate is an endogenous and most potent antioxidant. Even though there is considerable evidence linking low serum levels of urate to $\mathrm{PD},{ }^{75}{ }^{76} \mathrm{CSF}$ studies have shown inconsistent results. Maetzler et $a l^{77}$ found increase levels in PD compared with DLB, but Constantinescu et $a l^{78}$ showed no difference among parkinsonian groups and healthy controls.

\section{Inflammatory markers}

Fractalkine

Fractalkine is an inflammatory cytokine that acts as a neurotrophic and antiapoptotic factor in the central nervous system. It was decreased in MSA and could alone differentiate between PD and MSA with a sensitivity of $99 \%$ and a specificity of $95 \% .^{22}$ In addition, the fractalkine/A 342 ratio was closely associated with disease severity and progression in PD. These results are in need of replication.

\section{Complement $\mathrm{C} 3 /$ factor $\mathrm{H}$ ratio}

The $\mathrm{C} 3 /$ factor $\mathrm{H}$ ratio in CSF was significantly decreased in MSA compared with PD, AD and healthy controls. Increased

Table 4 CSF biomarkers for oxidative stress, inflammation and energy failure in parkinsonian disorders

\begin{tabular}{|c|c|c|c|c|}
\hline Research groups & Participants & Analyte & Method & Main findings \\
\hline Herbert et $a l^{73}$ & $\begin{array}{l}\text { PD } n=43, M S A n=23 \\
\text { controls } n=30\end{array}$ & DJ-1 & ELISA & $\begin{array}{l}\text { Increase in MSA>PD } \\
\text { Significant difference in MSA vs PD, } \\
\text { MSA vs controls and PD vs controls }\end{array}$ \\
\hline $\begin{array}{l}\text { Constantinescu } \\
\text { et } a l^{78}\end{array}$ & $\begin{array}{l}\text { PD } n=6, \text { MSA } n=13, \text { PSP } \\
n=18, C B D n=6, H C n=18\end{array}$ & Urate & Enzymatic method on a modular system & No difference \\
\hline Wennstrom et $a l^{47}$ & $\begin{array}{l}P D n=38, P D D n=22, D L B \\
n=33, A D n=46, H C n=52\end{array}$ & Neurosin & ELISA & $\begin{array}{l}\text { Lowest levels in DLB, but no } \\
\text { difference between synucleinopathies } \\
\text { When pooled, synucleinopathies } \\
\text { decrease levels vs AD+HC }\end{array}$ \\
\hline Goldstein et $a l^{82}$ & $\begin{array}{l}P D n=34, M S A n=54, P A F \\
n=20, H C n=38\end{array}$ & $\begin{array}{l}\text { Dihydroxyphenylatic acid } \\
\text { (DOPAC) }\end{array}$ & $\begin{array}{l}\text { Batch alumina extraction followed by liquid } \\
\text { chromatography with electrochemical detection }\end{array}$ & $\begin{array}{l}\text { Decrease in PD, MSA and to a lesser } \\
\text { degree PAF vs HC } \\
\text { No difference between } \\
\text { synucleinopathy groups }\end{array}$ \\
\hline Salvesen et $\mathrm{al}^{72}$ & $\begin{array}{l}\text { PD } n=30, \text { DLB } n=17, \text { MSA } \\
n=14, \text { PSP } n=19\end{array}$ & DJ-1 & ELISA & No difference among groups \\
\hline Maetzler et $a l^{77}$ & $\begin{array}{l}P D n=55, P D D n=20, \text { DLB } \\
n=20 \text {, controls } n=76\end{array}$ & Uric acid & ADVIA analyser+photometric methods & Increase in PD vs DLB \\
\hline Shi et $a l^{22}$ & $\begin{array}{l}\text { Discovery cohort: } \\
\text { PD } n=126, \text { MSA } n=32 \\
\text { AD } n=50 \text {, controls } n=137 \\
\text { Validation cohort: } \\
\text { PD } n=83\end{array}$ & $\begin{array}{l}\text { DJ-1 } \\
\text { Fractalkine }\end{array}$ & Bead-based multi-analyte assay (Luminex) & $\begin{array}{l}\text { DJ1: decrease in MSA+PD vs controls } \\
+A D \\
\text { Fractalkine: decrease in MSA vs PD, } \\
\text { AD+controls }\end{array}$ \\
\hline LeWitt et $a l^{81}$ & $\begin{array}{l}\text { PD } n=217 \text { (samples collected } \\
\times 2 \text { occasions) } \\
\text { HC } n=26\end{array}$ & $\begin{array}{l}\text { Homovallinic acid/ } \\
\text { xanthine ratio }\end{array}$ & Gas chromatography-mass spectrometry & $\begin{array}{l}\text { Increased ratio in PD vs } \mathrm{HC} \\
\text { Ratio increased further in PD } \\
\text { specimens collected up to } 2 \text { years } \\
\text { later }\end{array}$ \\
\hline Wang et $a l^{79}$ & $\begin{array}{l}P D n=86, M S A n=20, A D \\
n=38 H C n=91\end{array}$ & $\begin{array}{l}\text { Complement } \mathrm{C} 3 / \text { factor } \mathrm{H} \\
(\mathrm{FH})\end{array}$ & Bead-based multi-analyte assay (Luminex) & $\begin{array}{l}\text { C3: decrease in MSA vs PD+HC; } \\
\text { increase in AD vs all other groups } \\
\text { FH: increase in AD vs PD+HC } \\
\text { C3/FH ratio: decrease in MSA vs all } \\
\text { other groups }\end{array}$ \\
\hline Maetzler et $a l^{80}$ & $\begin{array}{l}\text { PD } n=38, P D D n=20, \text { DLB } \\
n=21 m \text {, controls } n=23\end{array}$ & Neprilysin & Fluorometric assay & Decrease in $\mathrm{DLB}+\mathrm{PDD}$ vs $\mathrm{PD}+$ controls \\
\hline Hong et $a l^{52}$ & $\begin{array}{l}P D n=117, A D n=50, H C \\
n=132\end{array}$ & DJ-1 & Bead-based multi-analyte assay (Luminex) & $\begin{array}{l}\text { Decreased levels in PD vs Controls } \\
\text { and } A D \\
\text { No difference between AD+ controls }\end{array}$ \\
\hline
\end{tabular}


levels of $\mathrm{C} 3$ or factor $\mathrm{H}$, together with decreased levels of A $\beta 42$, correlate positively with disease severity and progression in PD. ${ }^{79}$

\section{Neurosin}

Neurosin is a protein expressed in human brain tissue, and it is one of several enzymes suggested to cleave $\alpha$-Syn. A study comparing neurosin levels in synucleinopathies showed lowest levels in DLB, but no difference among DLB, PDD and PD. However, when pooled together, synucleinopathies had significantly lower neurosin levels compared with $\mathrm{AD}$ and controls. ${ }^{47}$

\section{Neprilysin}

Neprilysin is a membrane bound presynaptic protein involved in A $\beta$ clearance. CSF levels were significantly decreased in DLB and PDD compared with PD and controls, and they correlated well with $A \beta 42$ levels in all cohorts. ${ }^{80}$

\section{Catecholamine metabolites}

Homovanillic acid (HVA)/xanthine ratio

HVA is the major catabolite of dopamine and has been extensively studied in the past in relation to PD, as described above. Xanthine is the immediate precursor of urate. HVA/xanthine ratio was increased in PD compared with controls and correlated with diseased severity. ${ }^{81}$

\section{Dihydroxyphenylatic acid (DOPAC)}

Depletion of dopamine (a catecholamine) in basal ganglia is a defining neurochemical characteristic in PD. DOPAC is a neuronal metabolite of catecholamines. It was found to be decreased in PD and MSA compared with healthy controls, but there was no difference between synucleinopathy groups. ${ }^{82}$

The above compounds may be promising candidate makers, but they need verification in further studies. CSF HVA has been extensively studied in relation to PD and treatment response but still has no definite place in the clinical routine.

\section{Lysosomal dysfunction}

Lysosomes are the cell's waste disposal system, and their dysfunction is an early event in PD pathogenesis. ${ }^{83}$ Patients suffering from Gaucher disease, a rare, autosomal-recessive storage disorder caused by lysosomal enzyme $\beta$-glucocerebrosidase (GCase) deficiency, ${ }^{84}$ have an increased risk of parkinsonism, ${ }^{85}$ which appears to be driven by a direct effect of GCase deficiency and lysosomal dysfunction on $\alpha$-Syn aggregation. ${ }^{86}$

Measuring GCase activity in the CSF could be a useful biomarker in PD. $\mathrm{PD}^{87}$ and $\mathrm{DLB}^{88}$ patients were found to have significantly reduced GCase activity compared with neurological controls. A recent study showed that the combination of GCase activity, oligomeric/total $\alpha$-Syn ratio and age discriminates best PD from neurological controls. ${ }^{89}$ However, in a Dutch cohort of de novo PD patients and healthy controls, there was a trend towards a reduction in CSF GCase activity. ${ }^{90}$ The usefulness of GCase as a potential biomarker in parkinsonian conditions needs to be evaluated in future studies that include additional neurodegenerative groups to PD.

\section{'Omics' approaches}

The markers already discussed have been hypothesis driven based on pathophysiological studies, which have identified potentially deranged pathways in neurodegenerative diseases. The 'omics' techniques offer an unbiased approach of identifying biochemical pathways that are unexpectedly involved in neurodegeneration. Ultimately, the aim is to generate a list of candidate markers deserving further targeted studies. ${ }^{91}$ The 'omics' approach results in unbiased and systematic measurement of patterns of variations in genes (genomics), RNA (transcriptomics), proteins (proteomics) and small molecules (metabolomics). We have briefly discussed genomics and touched on metabolomics in previous sections, and we will now review proteomics in parkinsonian disorders.

Abdi et $a l^{92}$ used a multiplex quantitative proteomic platform to find 72 altered proteins in PD compared with healthy controls. Apolipoprotein $\mathrm{H}$ and ceruplasmin seemed to differentiate PD from healthy controls and from non-PD patients (AD and DLB). Eight of the proposed proteins were validated using a multianalyte CSF profile and showed good PD discriminatory power compared with $\mathrm{AD}$ and healthy controls. ${ }^{93}$

Using surface-enhanced laser desorption/ionisation time-of-flight mass spectrometry (SELDI-TOF MS), Constantinescu et al ${ }^{94}$ found a CSF proteomic profile consisting of four proteins (ubiquitin, $\beta 2$-microglobulin and two secretographin 1 fragments), which differentiated PD and healthy controls from atypical parkinsonian patients with an AUC of 0.8. Recently, Ishigami et $a l^{95}$ were able to differentiate PD from MSA, even at the early stages, using their proteomic pattern (ie, the combined set of many protein peaks), rather than a single peak. Multiple peaks differentiated MSA and PD from control groups, consistent with previous reports that a panel of potential biomarkers is essential to distinguish between disease states. $^{96}$

Another recent study attempted to differentiate PD from PDD patients using proteomic technology. Six proteins were identified, but only serin-protease inhibitor Serpin A1 was verified using biochemical methods. Performing 2-D immunoblots, there was $100 \%$ specificity and $58 \%$ sensitivity for the test procedure. $^{97}$ Testing CSF obtained from PD, PDD patients and non-demented controls using a gel-free proteomics mass spectrometry approach with isotope-labelled samples (iTRAQ) led to the identification of 16 differentially regulated proteins, which could be potentially diagnostic markers. ${ }^{98}$

While proteomics studies have produced a number of interesting candidate markers, these are still in need of replication and far from being established. It has also become clear that many of the protein expression changes seen so far represent changes that are common to several neurodegenerative diseases. Reliable detection of disease-specific changes most likely depends on the development of more advanced techniques that allow for deeper analyses of the CSF proteome.

\section{Imaging markers}

Even though imaging biomarkers are beyond the scope of this review, we would like to point out that combination of CSF and imaging markers can provide increased diagnostic accuracy compared with using either modality alone. For example, Borroni and colleagues used mid-sagittal midbrain-to-pons atrophy in addition to CSF tau fragments levels to increase the discriminative power in identifying PSP from other neurodegenerative conditions. ${ }^{66}$

\section{DISCUSSION}

The vast majority of the studies discussed are cross-sectional, retrospective and do not have pathological confirmation. The accuracy of the clinical diagnosis is uncertain, and the contribution of comorbidity to the clinical phenotype is unknown.

There is lack of standardisation both of preanalytical (sampling collection, handling and storage) and analytical (analysis execution/sample processing) factors. For example, CSF contamination by blood can alter study outcomes in $\alpha$-Syn and DJ-1 assays. In addition, there is lack of assay standardisation; 
different assays can give different absolute concentrations of the protein, making it almost impossible to use global reference limits and diagnostic cut-off points.

Furthermore, both disease groups and control groups are heterogeneous. The neurodegenerative groups differ in terms of age, disease duration and severity. The control groups include a very small proportion of healthy controls and are mostly nonneurodegenerative neurological patients. However, some studies include patients with possible neurodegenerative conditions, such as mild cognitive impairment or normal pressure hydrocephalus.

Finally, there is lack of combination of different biomarker modalities, such as imaging and CSF markers.

A very promising study is the Parkinson's Progression Markers Initiative (PPMI), which aims to identify PD progression markers and to better define subsets of PD patients. ${ }^{99} 100$ It is a 5 -year, multicentre, longitudinal study of drug-naïve PD patients with early-stage disease, compared with healthy controls. Detailed motor and neuropsychological assessments, DaT-scan and CSF examinations are performed. There is strict standardisation of data acquisition, CSF collection and processing. ${ }^{21}$

\section{SUMMARY POINTS: CSF BIOMARKERS IN PARKINSONISM}

- Aß42 has a role in predicting cognitive decline in Parkinson's disease (PD)

- t- $\alpha$-Syn: most promising marker; differentiates synucleinopathies from other neurodegenerative diseases and controls but is not specific

- t-tau and p-tau: inconsistent data, can help differentiate PD from $\mathrm{AD}$ and can be useful in combination with other markers

- NF-L: useful in differentiating PD from atypical parkinsonian conditions

- 4R-tau: possible marker of disease progression in PSP

- DJ1: potential role in discriminating MSA from PD

- Oxidative stress/inflammatory/metabolic markers: promising initial results, requiring further validation

\section{FUTURE DEVELOPMENTS FOR THE CSF FIELD IN PARKINSONISM}

We think that several hypothesis-driven biomarkers are going to be investigated at the same time using multiplex platforms. The proteomics field is likely to expand and gain in analytical sensitivity, resulting in the identification of more candidate markers, some of which may be unexpected and give new clues on disease mechanisms. There needs to be large, prospective and longitudinal cohorts with serial CSF examinations and pathological confirmation in as many patients as possible. A very important issue to be resolved is the standardisation of protocols and improvement in quality controls in CSF analysis. Finally, like in $\mathrm{AD}$, it will likely be important to combine several CSF markers with other modalities, like imaging.

Accurate diagnosis of parkinsonian conditions should occur as early as possible, before too much irreversible neuronal damage has accumulated. This is essential, especially with the emergence of potential disease-modifying drugs, which must be used to target the correct underlying pathology. There is promising progress in the development of an $\alpha$-Syn imaging agent, using radio ligands that bind to $\alpha$-Syn fibrils. This should enable the assessment of the distribution of brain $\alpha$-Syn during life. ${ }^{101}$

\section{CONCLUSION}

Parkinsonian conditions, like most neurodegenerative diseases, have complex and dynamic interaction of several underlying pathogenic mechanisms. A combination of biomarkers possibly from different modalities in large, longitudinal cohorts might be required for early diagnosis and accurate disease prognosis.

Acknowledgements We would like to thank Dr Janice Holton for kindly providing the pathological images.

Contributors All authors contributed to the design of this review. NM drafted the manuscript, and $\mathrm{HZ}$ and $\mathrm{AJL}$ revised it.

Funding NM is funded through the PSP association. $\mathrm{HZ}$ is funded through the Leonard Wolfson Experimental Neurology Centre.

\section{Competing interests None.}

Provenance and peer review Not commissioned; externally peer reviewed.

Open Access This is an Open Access article distributed in accordance with the Creative Commons Attribution Non Commercial (CC BY-NC 3.0) license, which permits others to distribute, remix, adapt, build upon this work non-commercially, and license their derivative works on different terms, provided the original work is properly cited and the use is non-commercial. See: http://creativecommons.org/ licenses/by-nc/3.0/

\section{REFERENCES}

1 Hughes AJ, Daniel SE, Kilford L, et al. Accuracy of clinical diagnosis of idiopathic Parkinson's disease: a clinico-pathological study of 100 cases. J Neurol Neurosurg Psychiatry 1992:55:181-4.

2 Fahn S. Secondary Parkinsonism. Sci Approaches Clin Neurol 1977:1159-89.

3 Spillantini MG, Schmidt ML, Lee VM-Y, et al. Alpha-synuclein in Lewy bodies. Nature 1997;388:839-40.

4 Gai WP, Power JHT, Blumbergs PC, et al. Multiple-system atrophy: a new alpha-synuclein disease? Lancet 1998;352:547-8.

5 Litvan I, Hauw J, Bartko JJ, et al. Validity and reliability of the preliminary NINDS neuropathologic criteria for progressive supranuclear palsy and related disorders. J Neuropathol Exp Neurol 1996;55:97-105.

6 Schneider JA, Watts RL, Gearing M, et al. Corticobasal degeneration: neuropathologic and clinical heterogeneity. Neurology 1997;48:959-69.

7 Constantinescu R. Cerebrospinal fluid biomarker candidates for Parkinsonian disorders. Front Neurol 2013;3:1-15.

8 Vekrellis K, Xilouri M, Emmanouilidou E, et al. Pathological roles of alpha-synuclein in neurological disorders. Lancet Neurol 2011;10:1015-25.

9 Giasson BI, Duda JE, Quinn SM, et al. Neuronal alpha-synucleinopathy with severe movement disorder in mice expressing A53T human alpha-synuclein. Neuron 2002;34:521-33.

10 Waxman EA, Giasson BI. Induction of intracellular tau aggregation is promoted by alpha-synuclein seeds and provides novel insights into the hyperphosphorylation of tau. J Neurosci 2011;31:7604-18.

11 Tsigelny IF, Crews L, Desplats $P$, et al. Mechanisms of hybrid oligomer formation in the pathogenesis of combined Alzheimer's and Parkinson's diseases. PLoS One 2008;3:e3135

12 Polymeropoulos MH, Lavedan C, Leroy E, et al. Mutation in the alpha-synuclein gene identified in families with Parkinson's disease. Science 1997;276:2045-7.

13 Cookson MR. DJ-1, PINK1, and their effects on mitochondrial pathways. Mov Disord 2010;25(Suppl 1):S44-8.

14 Hardy J, Lewis P, Revesz T, et al. The genetics of Parkinson's syndromes: a critical review. Curr Opin Genet Dev 2009;19:254-65.

15 Vandrovcova J, Anaya F, Kay V, et al. Disentangling the role of the tau gene locus in sporadic tauopathies. Curr Alzheimer Res 2010;7:726-34.

16 Hardy J. Genetic analysis of pathways to Parkinson's disease. Neuron 2010;68:201-6.

17 Biomarkers Definitions Working, G. Biomarkers and surrogate endpoints: preferred definitions and conceptual framework. Clin Pharmacol Ther 2001;69:89-95.

18 Gottfries CG, Gottfries I, Roos BE. Homovanillic acid and 5-hydroxyindoleacetic acid in the cerebrospinal fluid of patients with senile dementia, presenile dementia and parkinsonism. J Neurochem 1969;16:1341-5.

19 Curzon G, Godwin-Austen RB, Tomlinson EB, et al. The cerebrospinal fluid homovanillic acid concentration in patients with Parkinsonism treated with L-dopa. J Neurol Neurosurg Psychiatry 1970;33:1-6.

20 Eller M, Williams DR. Biological fluid biomarkers in neurodegenerative parkinsonism. Nat Rev Neurol 2009;5:561-70.

21 Kang JH, Irwin DJ, Chen-Plotkin AS, et al. Association of cerebrospinal fluid $\beta$-Amyloid 1-42, T-tau, P-tau 181, and $\alpha$-synuclein levels with clinical features of drug-naive patients with early Parkinson's disease. JAMA Neurol 2013;10:1277-87.

22 Shi M, Bradner J, Hancock AM, et al. Cerebrospinal fluid biomarkers for Parkinson's disease diagnosis and progression. Ann Neurol 2011;69:570-80.

23 Alves G, Bronnick K, Aarsland D, et al. CSF amyloid- $\beta$ and tau proteins, and cognitive performance, in early and untreated Parkinson's Disease: the Norwegian ParkWest study. J Neurol Neurosurg Psychiatry 2010;81:1080-6. 
24 Compta Y, Martí MJ, Ibarretxe-Bilbao N, et al. Cerebrospinal tau, phospho-tau, and beta-amyloid and neuropsychological functions in Parkinson's disease. Mov Disord 2009:24:2203-10.

25 Parnetti L, Tiraboschi P, Lanari A, et al. Cerebrospinal fluid biomarkers in Parkinson's disease with dementia and dementia with Lewy bodies. Biol Psychiatry 2008;64:850-5.

26 Hall S, Öhrfelt A, Constantinescu R, et al. Accuracy of a panel of 5 cerebrospinal fluid biomarkers in the differential diagnosis of patients with dementia and/or Parkinsonian disorders. Arch Neurol 2012;69:1445.

27 Parnetti L, Chiasserini D, Bellomo G, et al. Cerebrospinal fluid Tau/ $\alpha$-synuclein ratio in Parkinson's disease and degenerative dementias. Mov Disord 2011:26:1428-35.

28 Montine TJ, Shi M, Quinn JF, et al. CSF Abeta(42) and tau in Parkinson's disease with cognitive impairment. Mov Disord 2010;25:2682-5.

29 Sussmuth SD, Uttner I, Landwehrmeyer $B$, et al. Differential pattern of brain-specific CSF proteins tau and amyloid-beta in Parkinsonian syndromes. Mov Disord 2010;25:1284-8

30 Ohrfelt A, Grognet P, Andreasen N, et al. Cerebrospinal fluid alpha-synuclein in neurodegenerative disorders-a marker of synapse loss? Neurosci Lett 2009;450:332-5.

31 Compta Y, Pereira JB, Ríos J, et al. Combined dementia-risk biomarkers in Parkinson's disease: A prospective longitudinal study. Parkinsonism Relat Disord 2013;19:717-24

32 Bech S, Hjermind LE, Salvesen L, et al. Amyloid-related biomarkers and axonal damage proteins in parkinsonian syndromes. Parkinsonism Related Disord 2012:18:69-72.

33 Schoonenboom NS, Reesink FE, Verwey NA, et al. Cerebrospinal fluid markers for differential dementia diagnosis in a large memory clinic cohort. Neurology 2012:78:47-54

34 Andersson M, Zetterberg $\mathrm{H}$, Minthon L, et al. The cognitive profile and CSF biomarkers in dementia with Lewy bodies and Parkinson's disease dementia. Int $J$ Geriatr Psychiatry 2011;26:100-5.

35 Jellinger KA, Attems J. Prevalence and impact of vascular and Alzheimer pathologies in Lewy body disease. Acta Neuropathol 2008;115:427-36.

36 Ballard C, Ziabreva I, Perry R, et al. Differences in neuropathologic characteristics across the Lewy body dementia spectrum. Neurology 2006;67:1931-4.

37 Halliday $G$, Hely $M$, Reid $W$, et al. The progression of pathology in longitudinally followed patients with Parkinson's disease. Acta Neuropathol 2008;115:409-15.

38 Siderowf A, Xie SX, Hurtig H, et al. CSF amyloid \{beta\} 1-42 predicts cognitive decline in Parkinson's disease. Neurology 2010;75:1055-61.

39 Stefanis L. alpha-Synuclein in Parkinson's disease. Cold Spring Harb Perspect Med 2012:2:a009399.

40 Henchcliffe C, Dodel R, Beal MF. Biomarkers of Parkinson's disease and Dementia with Lewy bodies. Prog Neurobiol 2011;95:601-13.

41 Ohrfelt $A$, Zetterberg $H$, Andersson $K$, et al. Identification of novel alpha-synuclein isoforms in human brain tissue by using an online nanoLC-ESI-FTICR-MS method. Neurochem Res 2011;36:2029-42.

42 Conway KA, Lee S-J, Rochet J-C, et al. Acceleration of oligomerization, not fibrillization, is a shared property of both alpha-synuclein mutations linked to early-onset Parkinson's disease: implications for pathogenesis and therapy. Proc Natl Acad Sci USA 2000;97:571-6.

43 Aerts MB, Esselink RA, Abdo WF, et al. CSF $\alpha$-synuclein does not differentiate between parkinsonian disorders. NBA 2012;33:430.e1-e3.

44 Noguchi-Shinohara M, Tokuda T, Yoshita M, et al. CSF alpha-synuclein levels in dementia with Lewy bodies and Alzheimer's disease. Brain Res 2009:1251:1-6.

45 Spies PE, Melis RJ, Sjögren MJ, et al. Cerebrospinal fluid alpha-synuclein does not discriminate between dementia disorders. J Alzheimers Dis 2009;16:363-9.

46 van Dijk KB, Weiss M, Raijmakers $A$, et al. Reduced a-synuclein levles in cerebrospinal fluid in Parkinson's disease are unrelated to clinical and imaging measures of disease severity. Eur J Neurol 2013;3:388-94.

47 Wennström M, Surova Y, Hall S, et al. Low CSF Levels of both $\alpha$-synuclein and the $\alpha$-synuclein cleaving enzyme neurosin in patients with synucleinopathy. PLOS ONE 2013;8:e53250

48 Mollenhauer B, Trautmann E, Taylor $\mathrm{P}$, et al. Total CSF $\alpha$-synuclein is lower in de novo Parkinson patients than in healthy subjects. Neurosci Lett 2013;532:44-8.

49 Tateno F, Sakakibara R, Kawai T, et al. Alpha-synuclein in the cerebrospinal fluid differentiates synucleinopathies (Parkinson Disease, dementia with Lewy bodies, multiple system atrophy) from Alzheimer disease. Alzheimer Dis Assoc Disord 2012:26:213-16

50 Wang Y, Shi M, Chung KA, et al. Phosphorylated $\alpha$-synuclein in Parkinson's disease. Sci Transl Med 2012:4:121ra20.

51 Mollenhauer B, Schulz-Schaeffer WJ, Schlossmacher MG. CSF $\alpha$-synuclein, tau, and amyloid $\beta$ in Parkinson's disease. Authors' reply. Lancet Neurol 2011;10:681-3.

52 Hong Z, Chung KA, Quinn JF, et al. DJ-1 and $\alpha$-synuclein in human cerebrospinal fluid as biomarkers of Parkinson's disease. Brain 2010;133:713-26.

53 Mollenhauer B, Cullen V, Kahn I, et al. Direct quantification of CSF alpha-synuclein by ELISA and first cross-sectional study in patients with neurodegeneration. Exp Neurol 2008;213:315-25
54 Mollenhauer B, Locascio JJ, Schulz-Schaeffer W, et al. $\alpha$-Synuclein and tau concentrations in cerebrospinal fluid of patients presenting with parkinsonism: a cohort study. Lancet Neurol 2011:10:230-40.

55 Tokuda T, Salem SA, Allsop D, et al. Decreased alpha-synuclein in cerebrospinal fluid of aged individuals and subjects with Parkinson's disease. Biochem Biophys Res Commun 2006;349:162-6.

56 Blennow K, Hampel $\mathrm{H}$, Weiner $\mathrm{M}$, et al. Cerebrospinal fluid and plasma biomarkers in Alzheimer's disease. Nat Rev Neurol 2010:6:131-44.

57 Tokuda T, Qureshi MM, Ardah MT, et al. Detection of elevated levels of $\alpha$-synuclein oligomers in CSF from patients with Parkinson's disease. Neurology 2010;75:1766-70

58 Park MJ, Cheon S-M, Bae H-R, et al. Elevated levels of $\alpha$-synuclein oligomer in the cerebrospinal fluid of drug-naive patients with Parkinson's disease. J Clin Neurol 2011:7:215.

59 Sierks MR, Chatterjee G, McGraw C, et al. CSF levels of oligomeric alpha-synuclein and beta-amyloid as biomarkers for neurodegenerative disease. Integr Biol 2011;3:1188.

60 Foulds PG, Yokota O, Thurston A, et al. Post mortem cerebrospinal fluid $\alpha$-synuclein levels are raised in multiple system atrophy and distinguish this from the other $\alpha$-synucleinopathies, Parkinson's disease and Dementia with Lewy bodies. Neurobiol Dis 2012:45:188-95.

61 Kouri N, Whitwell JL, Josephs KA, et al. Corticobasal degeneration: a pathologically distinct 4R tauopathy. Nat Rev Neurol 2011;7:263-72.

62 Goedert M, Spillantini MG, Potier MC, et al. Cloning and sequencing of the CDNA encoding an isoform of microtubule-associated protein tau containing four tandem repeats: differential expression of tau protein mRNAs in human brain. EMBO 1989:8:393-9.

63 de Silva R, Lashley T, Gibb G, et al. Pathological inclusion bodies in tauopathies contain distinct complements of tau with three or four microtubule-binding repeat domains as demonstrated by new specific monoclonal antibodies. Neuropathol Appl Neurobiol 2003;29:288-302.

64 Luk C, Compta Y, Magdalinou N, et al. Development and assessment of sensitive immuno-PCR assays for the quantification of cerebrospinal fluid threeand four-repeat tau isoforms in tauopathies. J Neurochem 2012;123:396-405.

65 Borroni B, Malinverno M, Gardoni F, et al. Tau forms in CSF as a reliable biomarker for progressive supranuclear palsy. Neurology 2008:71:1796-803.

66 Borroni B, Malinverno M, Gardoni F, et al. A combination of CSF tau ratio and midsaggital midbrain-to-pons atrophy for the early diagnosis of progressive supranuclear palsy. J Alzheimers Dis 2010;22:195-203.

67 Kuiperij HB, Verbeek MM. Diagnosis of progressive supranuclear palsy: can measurement of tau forms help? Neurobiol Aging 2012:33:204 e17-18.

68 Meredith JE Jr, Sankaranarayanan S, Guss V, et al. Characterization of Novel CSF Tau and ptau Biomarkers for Alzheimer's Disease. PLoS One 2013;8:e76523.

69 Lasec R. Studying the intrinsic determinants of neuronal form and function. Intrinsic Determinants of Neuronal Form and Function, 1988:1-60.

70 Brettschneider J, Petzold A, Süssmuth SD, et al. Neurofilament heavy-chain NfH (SMI35) in cerebrospinal fluid supports the differential diagnosis of Parkinsonian syndromes. Mov Disord 2006;21:2224-7.

71 Constantinescu R, Rosengren L, Johnels B, et al. Consecutive analyses of cerebrospinal fluid axonal and glial markers in Parkinson's disease and atypical parkinsonian disorders. Parkinsonism Relat Disord 2010;16:142-5.

72 Salvesen L, Bech S, Lokkegaard A, et al. The DJ-1 concentration in cerebrospinal fluid does not differentiate among parkinsonian syndromes. Parkinsonism Relat Disord 2012;18:899-901.

73 Herbert MK, Eeftens JM, Aerts MB, et al. CSF levels of DJ-1 and tau distinguish MSA patients from PD patients and controls. Parkinsonism Relat Disord 2013;1:1-4.

74 Gmitterova K, Heinemann U, Gawinecka J, et al. 8-OHdG in cerebrospinal fluid as a marker of oxidative stress in various neurodegenerative diseases. Neurodegener Dis 2009:6:263-9.

75 Davis JW, Grandinetti A, Waslien CJ, et al. Observations on serum uric acid levels and the risk of idiopathic Parkinson's disease. Am J Epidemiol 1996;144:480-4.

76 Annanmaki T, Muuronen A, Murros K. Low plasma uric acid level in Parkinson's disease. Mov Disord 2007;22:1133-7.

77 Maetzler W, Stapf AK, Schulte C, et al. Serum and cerebrospinal fluid uric acid levels in lewy body disorders: associations with disease occurrence and amyloid-beta pathway. J Alzheimers Dis 2011;27:119-26.

78 Constantinescu R, Andreasson U, Holmberg B, et al. Serum and cerebrospinal fluid urate levels in synucleinopathies versus tauopathies. Acta Neurol Scand 2013;127: e8-12.

79 Wang Y, Hancock AM, Bradner J, et al. Complement 3 and factor $h$ in human cerebrospinal fluid in Parkinson's disease, Alzheimer's disease, and multiple-system atrophy. Am J Pathol 2011;178:1509-16.

80 Maetzler W, Stoycheva V, Schmid B, et al. Neprilysin activity in cerebrospinal fluid is associated with dementia and amyloid-beta42 levels in Lewy body disease. J Alzheimers Dis 2010:22:933-8.

81 LeWitt $\mathrm{P}$, Schultz L, Auinger $\mathrm{P}$, et al. CSF xanthine, homovanillic acid, and their ratio as biomarkers of Parkinson's disease. Brain Res 2011;1408:88-97. 
82 Goldstein DS, Holmes C, Sharabi Y. Cerebrospinal fluid biomarkers of central catecholamine deficiency in Parkinson's disease and other synucleinopathies. Brain 2012;135:1900-13.

83 Parnetti L, Castrioto A, Chiasserini D, et al. Cerebrospinal fluid biomarkers in Parkinson's disease. Nat Rev Neurol 2013;3:131-40.

84 Brady RO, Kanfer J, Shapiro D. The metabolism of glucocere-brosides. I. Purification and properties of glucocerebrosidase-cleaving enzyme from spleen tissue. J Biol Chem 1965;240:39-43.

85 Sidransky E, Nalls MA, Aasly J0, et al. Multicenter analysis of glucocerebrosidase mutations in Parkinson's disease. N Engl J Med 2009;361:1651-61.

86 Mazzulli JR, Xu YH, Sun Y, et al. Gaucher disease glucocerebrosidase and alpha-synuclein form a bidirectional pathogenic loop in synucleinopathies. Cell 2011;146:37-52.

87 Balducci C, Pierguidi L, Persichetti E, et al. Lysosomal hydrolases in cerebrospinal fluid from subjects with Parkinson's disease. Mov Disord 2007;22:1481-4.

88 Parnetti L, Balducci C, Pierguidi L, et al. Cerebrospinal fluid beta-glucocerebrosidase activity is reduced in Dementia with Lewy Bodies. Neurobiol Dis 2009;34:484-6.

89 Parnetti L, Chiasserini D, Persichetti E, et al. Cerebrospinal fluid lysosomal enzymes and alpha-synuclein in Parkinson's disease. Mov Disord 2014. doi:10.1002/mds. 25772. (Epub ahead of print).

90 van Dijk KD, Persichetti E, Chiasserini $D$, et al. Changes in endolysosomal enzyme activities in cerebrospinal fluid of patients with Parkinson's disease. Mov Disord 2013;28:747-54.

91 Caudle WM, Bammler TK, Lin Y, et al. Using 'omics' to define pathogenesis and biomarkers of Parkinson's disease. Expert Rev Neurother 2010;10:925-42.

92 Abdi F, Quinn JF, Jankovic J, et al. Detection of biomarkers with a multiplex quantitative proteomic platform in cerebrospinal fluid of patients with neurodegenerative disorders. J Alzheimer's Dis 2006;9:293-348.
93 Zhang J, Sokal I, Peskind ER, et al. CSF Multianalyte Profile Distinguishes Alzheimer and Parkinson Diseases. Am J Clin Pathol 2008;129:526-9.

94 Constantinescu R, Andreasson U, Li S, et al. Proteomic profiling of cerebrospinal fluid in parkinsonian disorders. Parkinsonism Relat Disord 2010;16:545-9.

95 Ishigami N, Tokuda T, Ikegawa M, et al. Cerebrospinal fluid proteomic patterns discriminate Parkinson's disease and multiple system atrophy. Mov Disord 2012;27:851-7.

96 Mattison HA, Stewart T, Zhang J. Applying bioinformatics to proteomics: Is machine learning the answer to biomarker discovery for PD and MSA? Movement Disorders 2012:27:1595-7.

97 Jesse $\mathrm{S}$, Lehnert $\mathrm{S}$, Jahn 0 , et al. Differential sialylation of serpin A1 in the early diagnosis of Parkinson's disease dementia. PLoS One 2012;7:e48783.

98 Lehnert $\mathrm{S}$, Jesse $\mathrm{S}$, Rist $\mathrm{W}$, et al. iTRAQ and multiple reaction monitoring as proteomic tools for biomarker search in cerebrospinal fluid of patients with Parkinson's disease dementia. Exp Neurol 2012;234:499-505.

99 The Lancet N. Biomarker promise for Parkinson's disease. Lancet Neurol 2010;9:1139.

100 Parkinson Progression Marker I. The Parkinson Progression Marker Initiative (PPMI). Prog Neurobiol 2011;95:629-35.

101 Bagchi DP, Yu L, Perlmutter JS, et al. Binding of the radioligand SIL23 to alpha-synuclein fibrils in Parkinson disease brain tissue establishes feasibility and screening approaches for developing a Parkinson disease imaging agent. PLOS ONE 2013:8:e55031.

102 Kuiperij HB, Verbeek MM, Borroni B. Tau forms in CSF as a reliable biomarker for progressive supranuclear palsy. Neurology 2011;76:1443; author reply 1443.

103 Borroni B, Malinverno M, Gardoni F, et al. A combination of CSF tau ratio and midsaggital midbrain-to-pons atrophy for the early diagnosis of progressive supranuclear palsy. J Alzheimer 's Dis 2010;22:195-203. 